\title{
Study of different factors affecting Agrobacterium - mediated genetic transformation in lentil (Lens culinaris Medik.)
}

\author{
Das S. K. ${ }^{1}{ }^{*}$, Hoque M. I. ${ }^{2}$ and. Sarker R. H. ${ }^{2}$ \\ ${ }^{1}$ Department of Botany, University of Barisal, Barisal-8200, Bangladesh. \\ 2 Department of Botany, University of Dhaka, Dhaka-1000, Bangladesh.
}

Publication history: Received on 19 August 2018; revised on 13 September 2018; accepted on 21 September 2018

Article DOI: https://doi.org/10.30574/gscbps.2018.5.1.0087

\begin{abstract}
The present work was aimed to study the various factors affecting Agrobacterium tumefaciens mediated genetic transformation of three BARI masur variety of lentil (Lens culinaris Medik.), namely, BM-4, BM-5 and BM-6. Agrobacterium strain LBA4404 containing plasmid pBI121 which carrying gus and nptII as screenable and selectable marker genes, respectively, was used for transformation. Factors affecting transformation efficiency, such as, type of explants, bacterial density, incubation time and co-cultivation period were studied. The result showed that decapitated embryo (DE) explants of BM-6 variety of lentil inoculated in Agrobacterium suspensions at density of 1.0 (OD 600 ) for 45 minutes and co-cultivated on MS medium with hormones in the dark for 3 days gave the highest transient expression of gus gene (86.90\%). The lowest percentage (15.00\%) of GUS +ve explants observed in cotyledonary node (CN) of BM5 variety of lentil when they were inoculated in Agrobacterium suspensions at density of 0.5 (OD 600$)$ for 15 minutes. Using this protocol agronomical and economically important trait could be transfer to the locally grown lentil varieties.
\end{abstract}

Keywords: Lentil; Bacterial density; Incubation; Co-cultivation; Agrobacterium; Transformation

\section{Introduction}

Lentils have been the part of the human diet since the aceramic (before pottery) Neolithic times. It is one of the first crops domesticated in the Near East and still the most important cool season annual pulse crops throughout the world. It is preferred over the other pulses by consumer's preference all over the world. This important grain legume gained worldwide economic importance as a source of protein for human and animal nutrition. In Bangladesh, people like eating only red cotyledon type of lentil, where it is often eaten as a product "Dhal" as a main dish, side dish, salads or with flat bread (Roti) or rice. Khichuri is another popular dish, which is made from a mixture of split lentil seeds and rice.

From the above discussion, it is evident that lentil is highly nutritious. The demand for this crop has been steadily increasing in the Indian subcontinent for its nutritional value, cooking quality and easy digestibility. On a global scale, lentil consumption is rising at a rate more than twice that of the human population growth. We expect that by 2030 , world lentil consumption will be double.

Although lentil is considered as an important pulse crop for many parts of the world but its production in most countries is usually characterized by low yield potential. Several factors are supposed to be responsible for the lower production of this important crop which includes susceptibility to disease, pests, fungi, massive flower drop, post-harvest loss, and management problem. Besides this, several abiotic stresses such as cold, drought, heat, salinity, nutrient deficiency and nutrient toxicity adversely affect lentil yields worldwide [1-3].

\footnotetext{
*Corresponding author

E-mail address: mrsubroto@yahoo.com
} 
Das et al. / GSC Biological and Pharmaceutical Sciences 2018, 05(01), 034-042

It is clear that there is a need to increase productivity, enhance the nutritional value and other desired agronomic quality of this crop. Cultivars resistant to biotic and abiotic stresses and better protein quality and quantity are required.

Conventional breeding methods including hybridization technique and selection are being carried out to develop improved varieties in a wide range of crops. But in lentil, the progress of improvement through conventional breeding is hampered due to lack of genetic variability which caused by a predominantly high degree of self-pollination and absence of resistance gene/s of interest in the existing germplasm. Moreover, hybridization between microsperma and macrosperma is hampered due to asynchronous flowering and small size of flowers. Besides these, it takes long time to incorporate agronomic traits using conventional breeding method.

However, now it is possible to introduce genes into crop plants in a relatively short period of time using the recent advances in genetic engineering of plants [4]. Thus genetic transformation combined with traditional breeding techniques, could aid in improving both the quality and yield of lentil [5-7].

To identify the integration of gene/s of interest into plant cell, a specific screenable marker gene and one or more selectable marker gene are requiredin all transformation experiments. In this case generally GUS (glucoronidase) gene and neomycin phosphotransfrerase termed as nptII (kanamycin resistant) gene have been used for screenable and selectable marker gene, respectively. This reporter gene can be recognized in plant tissue with the help of selectable marker agents, confirming transformation of the plant tissue (through histochemical GUS assay). In this way one can understand that the plant tissue subjected for transformation has really been transformed or not [8].

However transformation efficiency was depended on many factors such as type of Agrobacterium strain, genotype (host) compatibility and responsiveness of explants toward Agrobacterium infection, optical density (O.D.) of Agrobacterium suspensions, incubation and co-cultivation period were optimized in conducting transformation experiments. Moreover, the efficiency of transformation and transgenic plant production depends on the establishment of suitable protocols including the co-cultivation of host cell/tissue, regeneration and selection of transgenic plantlets.

Ding et al., [9] obtained more than 100 putative transgenic after pre-culturing the explants for three days before infection with Agrobacterium. Zhang et al. [10] noted that in Chinese cabbage, co-cultivation for 2 days yielded the highest transformation frequency whereas in chickpea Krishnamurthy et al. [11] were able to obtain transgenic plants by using co-cultivation of explants for 3 days.

From the above background information of transformation the present study was conducted to see the effect of explants, bacterial density, incubation time, and co-cultivation period on genetic transformation of lentil.

\section{Material and methods}

Three microsperma varieties of lentil (Lens culinaris Medik) namely, BARI Masur-4 (BM-4), BARI Masur-5 (BM-5) and BARI Masur-6 (BM-6) cultivated in Bangladesh were used as the plant materials for this investigation. Seeds of these three varieties of lentil were collected from Bangladesh Agricultural Research Institute (BARI), Joydebpur, Gazipur and maintained in the Plant Breeding and Biotechnology Laboratory of the Department of Botany, University of Dhaka. Three different explants namely, cotyledonary node (CN), cotyledon attached decapitated embryo (CADE) and Decapitated embryo (DE) were used for genetic transformation of lentil. For seed germination, the seeds were first soaked in $70 \%$ ethanol for 1 minute and then they were surface sterilized with $0.1 \% \mathrm{HgCl}_{2}$ solution for 15 minutes. Seeds were then washed three - four times with sterilized distilled water. The surface sterilized seeds were then cultured on $0.3 \%$ water agar medium for germination.

Cotyledonary node explants were collected from three days old germinated seedlings following the removal of seed coats. The shoot and root tip portion were excised and discarded. CADE and DE explants were collected from overnight soaked sterilized seeds. The seed coats are removed and the seeds were split open and two cotyledons were separated. Before inoculation the shoot and root meristems from these embryos were excised. In cotyledon attached decapitated embryo explants, one part of cotyledon with embryos attached to it and sliced embryos were cultured. Explants were then placed on MS medium with or without supplemented with $0.5 \mathrm{mg} / \mathrm{l} \mathrm{BAP}+0.5 \mathrm{mg} / \mathrm{l} \mathrm{Kn}+0.1 \mathrm{mg} / \mathrm{l} \mathrm{GA} 3+5.5 \mathrm{mg} / \mathrm{l}$ tyrosin for regeneration of shoots. The cultures were maintained under fluorescent illumination on a $16 \mathrm{~h}$ photoperiod at $25 \pm 2^{\circ} \mathrm{C}$.

Agrobacterium tumifaciens strain LBA4404 with the binary plasmid pBI121 (figure 1) was used for transformation experiments. The binary vector $\mathrm{pBI} 121$ has the background of pBIN19. It contains a scoreable reporter gene GUS ( $\beta$ glucurunidase) driven by a CaMV35S promoter and NOS terminator and a selectable marker gene $n p t I I$ fused between 
NOS promoter and NOS terminator encoding for the enzyme neomycin phosphotransferase conferring kanamycin resistance [12]. Fifty $\mathrm{ml}$ of liquid YMB containing $50 \mathrm{mg} / \mathrm{l}$ kanamycin was inoculated with Agrobacterium from a fresh bacterial plate and grown at $180 \mathrm{rpm}$ on a rotary shaker at $28^{\circ} \mathrm{C}$ for $16 \mathrm{~h}$ following the method done by Hooykaas [13].

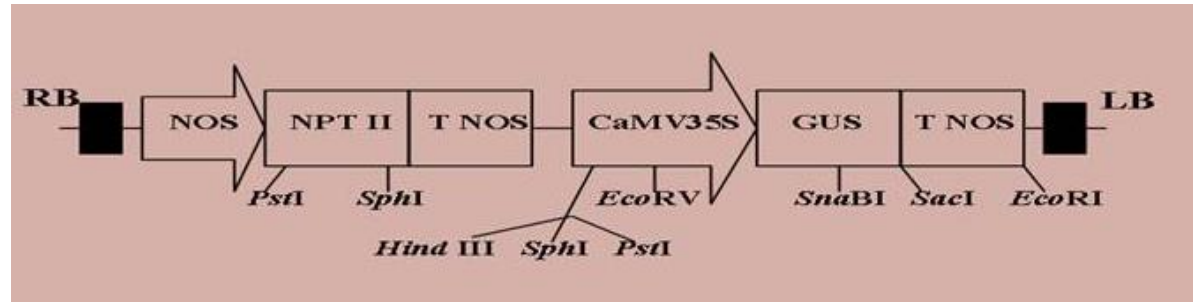

Figure 1 Diagrammatic representation of Agrobacterium tumefaciens strain LBA4404 containing plasmids pBI121 showing a part of T-DNA between left and right border

To prepare the Agrobacterium suspension overnight grown Agrobacterium culture taken from bacterial plate was centrifuged for 10 minutes at $5000 \mathrm{rpm}$ and the pellet was re-suspended in liquid MS medium (pH 5.8). This Agrobacterium suspension was used for infection of explants. Before doing infection of the explants "Optical Density" or O.D. of the bacterial suspension was determined at $600 \mathrm{~nm}$ with the help of a spectrophotometer (Shimadzu, Japan). To perform suitable and sufficient infection of the explants, lightly injured explants were dipped in bacterial suspension for different incubation periods. Following infection and incubation, the explants were soaked in filter papers for a short period of time to remove excess bacterial suspension before transferring them to co-cultivation medium. Then explants were maintained in co-culture medium for 2 - 4 days in dark condition on MS media with or without growth regulators.

Transformation ability of the explants was monitored by GUS histochemical assay [14, 15]. In this assay transformed explants shows insoluble indigo blue colour at the site of the cut end for GUS enzyme activity. Thus, it allows transformed tissues to be screened histochemically. For monitoring stable GUS expression tissues and shoots were kept under selection pressure of around two months.

\subsection{Preparation of MS media}

Commercially available dry powdered MS medium (Duchefa Biocheme, Netharlands) containing all the constituents of MS medium (inorganic salts, vitamins and amino acids) except sucrose and agar were used to prepare medium for in vitro regeneration of plants. Appropriate amount of MS powder is dissolved in distilled water $(10 \%$ less than the final volume of the medium), and after adding sucrose (3\%), the $\mathrm{pH}$ was adjusted to 5.8. To prepare agar solidified media, $0.8 \%$ agar was added.

\subsection{Preparation of Agrobacterium culture media}

For the growth of Agrobacterium tumefaciens, YMB medium was used. This media was prepared in the following manner:

Table 1 Composition of YMB media

\begin{tabular}{lc}
\hline Components & $\begin{array}{l}\text { Concentration of components in } \\
\text { gram per 1000 ml medium }\end{array}$ \\
\hline Yeast Extract & 0.4 \\
Mannitol & 10.0 \\
$\mathrm{NaCl}$ & 0.1 \\
$\mathrm{MgSO}_{4.7 \mathrm{H}_{2} \mathrm{O}}$ & 0.2 \\
$\mathrm{~K}_{2} \mathrm{HPO}_{4}$ & 0.5 \\
\hline
\end{tabular}

All the above ingredients of the medium were added in $750 \mathrm{ml}$ distilled water and mixed properly. Then the final volume was made up to $1000 \mathrm{ml}$ by adding distilled water. The $\mathrm{pH}$ was adjusted at $7.0-7.2$ before autoclaving the media. 
To prepare working culture medium (to make bacterial suspension), liquid YMB medium was used whereas; maintenance medium was prepared by adding $7.5 \mathrm{~g}$ agar to the medium before autoclaving. Filter sterilized antibiotic kanamycin (100 mg/l), streptomycin (50 mg/l) and rifampicin (10 mg/l) was added to the autoclaved and cooled liquid medium (working) prior to bacterial inoculation. The medium was then poured into petri plates and these culture plates were stored at $4^{\circ} \mathrm{C}$. After solidification, the media were ready for bacterial culture.

\subsection{Preparation of GUS assay solution}

For the preparation of GUS staining solution following steps were followed-

Firstly few drops of DMSO (Dimethyle sulphoxide) were taken in a beaker and 0.9 gm of X-gluc was added. The beaker was kept in shaker and gently shaken until X-gluc was completely dissolve. Then $2 \mathrm{ml}$ of Chloramphenical was added into the beaker. After that, $1 \mathrm{ml}$ of $10 \%$ titron X was added to the X-gluc solution and Finally 20 ml methanol was added to the solution and gently mixed. The $\mathrm{pH}$ was adjusted to 7.15 by adding $\mathrm{pH}-10$ buffer solution.

\section{Results and discussion}

\subsection{Optimization of different parameters influencing transformation efficiency of explants}

Available reports on Agrobacterium-mediated genetic transformation indicate that, transformation efficiency is influenced by several factors such as optical density (O.D.) of Agrobacterium suspensions, incubation time, cocultivation period and culture media for co-cultivation of explants etc. Optimizations of these conditions were done by monitoring transient expression of the GUS reporter gene after co-cultivation of explants in Agrobacterium strains LBA4404 containing binary plasmid pBI121.

\subsection{Influence of optical density (O.D.) and incubation period of Agrobacterium suspension on transformation}

A specific density and time period is required by Agrobacterium for its attachment and for transfer of its T- DNA to explants. Less incubation time period, of course produces low number of transformed explants whereas higher time period can also be lethal due to overgrowth of Agrobacterium that behaves as parasites with to explants and hence low frequency of transformation is occurred.

In this experiment the relationship between optical density and incubation period of Agrobacterium suspension as well as transformation efficiency of explants were studied. For this purpose optical density (O.D.) was measured at $600 \mathrm{~nm}$ and bacterial suspension with optical density of $0.5,0.8,1.0$ and 1.2 having incubation period of 30, 45 and 60 and 75 minutes were used in these experiments. Transformation efficiency was found to increase with the increased optical density. Maximum percentage of transformation was observed at O.D of 1.0 and 1.2. At O.D of 1.2 the percentage of GUS positive explants was 80 , whereas minimum transient GUS expression (15 \%) was recorded at 0.D. of 0.5 (table 2).

These experiments also exhibited that the percentage of GUS positive explants was increased with the increase of incubation period but increase of the percentage of GUS positive explants was not remarkable beyond 45 minutes of incubation. The maximum percentage of GUS positive explants was observed at 45 and 60 minutes of incubation at O.D of 1.2 (table 2). It was also observed that when the duration of incubation and optical density of the bacterial suspension was more than 60 minutes and 1.0 respectively then overgrowth of bacteria in the co-cultured plates was observed which hampered desired regeneration capability of the explants. In some cases overgrowth of bacteria was noticed following one or two subcultures when the explants were treated with the above mentioned conditions. This undesired overgrowth of bacteria can be checked when bacterial suspension had an O.D. of 1.0 with incubation period of 45 min. Therefore, the optimum incubation period for the explants was found to be 45 minutes with optical density of 1.0.

Jaiwal et al. [16] also reported such results where the highest transformation efficiency in Vigna radiata at 0.D. of 1.0. A similar result has also been reported in many plant species, such as alfalfa [17], oil palm [18] and chickpea [11]. 
Table 2 Influence of optical density (measured at $600 \mathrm{~nm}$ ) of Agrobacterium suspension and effect of different incubation periods on Agrobacterium-mediated transformation of various explants of BM - 5 variety of lentil analyzed through transient GUS histochemical assay

\begin{tabular}{|c|c|c|c|c|c|}
\hline O.D 600 & $\begin{array}{l}\text { Incubation } \\
\text { period (min) }\end{array}$ & $\begin{array}{l}\text { Number of } \\
\text { explants } \\
\text { infected }\end{array}$ & $\begin{array}{l}\text { Number of explants } \\
\text { assayed for GUS }\end{array}$ & $\begin{array}{c}\text { Number of GUS+ve } \\
\text { explants }\end{array}$ & $\begin{array}{c}\text { Percentage of } \\
\text { GUS+ve explants } \\
\text { (\%) }\end{array}$ \\
\hline \multirow{4}{*}{0.5} & 15 & 50 & 20 & 3 & 15 \\
\hline & 30 & 50 & 20 & 4 & 20 \\
\hline & 45 & 50 & 20 & 5 & 25 \\
\hline & 60 & 50 & 20 & 7 & 35 \\
\hline \multirow{4}{*}{0.8} & 15 & 50 & 20 & 6 & 30 \\
\hline & 30 & 50 & 20 & 6 & 30 \\
\hline & 45 & 50 & 20 & 8 & 40 \\
\hline & 60 & 50 & 20 & 9 & 45 \\
\hline \multirow{4}{*}{1.0} & 15 & 50 & 20 & 6 & 30 \\
\hline & 30 & 50 & 20 & 9 & 45 \\
\hline & 45 & 50 & 20 & 16 & 80 \\
\hline & 60 & 50 & 20 & 16 & 80 \\
\hline \multirow{4}{*}{1.2} & 15 & 50 & 20 & 10 & 50 \\
\hline & 30 & 50 & 20 & 13 & 65 \\
\hline & 45 & 50 & 20 & 16 & 80 \\
\hline & 60 & 50 & 20 & 16 & 80 \\
\hline
\end{tabular}

\subsection{Influence of co-cultivation period on transformation}

Transformation frequency and duration of co-cultivation have been reported to be directly correlated as has been described in peas [20]. In most of the transformation experiments 2 to 3 days of co-cultivation period was used as has been reported in tobacco [21]. However, Arundhati [22] reported increased frequency (47.8\%) of transformation when leaf discs explants of pigeon pea were co-cultured for a period of 4 days. These results revealed that duration of infection and co-cultivation are genotype specific and has great influence on transformation frequency.

In the present investigation four different co-cultivation periods ranging from 2 - 5 days were tried to find out the optimum co-cultivation period. It was found that, percentage of transformation could be increased with the increase of co-cultivation period at a constant optical density (1.0) of bacterial suspension and a constant incubation period of 45 minutes. Although percentage of GUS positive explants increased with the increase of co-cultivation period, it was also observed that a co-cultivation for more than 3 days sometimes promoted overgrowth of bacteria (figure 2). As a result good number of explants in co-culture media was found to suffer from poor health and became brown thus failed to regenerate. Therefore, 3 days of co-cultivation period was found to be optimum for transformation.

In chickpea Krishnamurthy et al. [11] incubated mature embryo explants for 20 minutes and then co-cultivated the explants for 3 days and were able to obtain transgenic plants. Tewari-Singh et al. [23] employed the same co-cultivation period of 3 days but incubated explants in bacterial suspension for 1- 2 hours and got transgenic plant. In the present study it was found that, such longer period of incubation (more than 45 minutes) and co-cultivation (more than 3 days) reduced survivability of explants and lead bacterial overgrowth in culture medium thus hampering the proper growth of infected explants. Warkentin and McHugen [24] reported that, they were able to observe transient GUS expression from inoculating lentil epicotyl explants incubated only for 10 - 15 minutes, but they did not mention the information on transformation frequency. In the same report they also mentioned that longer co-culture period was capable of enhancing the explants area for GUS expression. Although the inoculation period differs but their observation supports present results regarding the expression of GUS gene. 


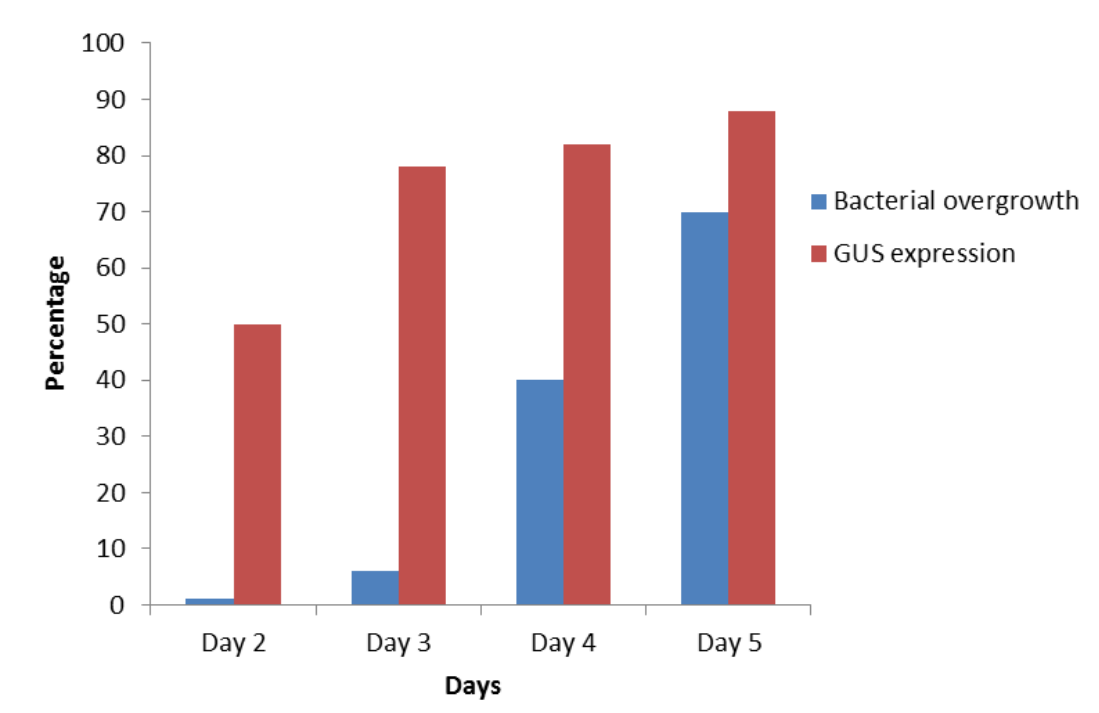

Figure 2 Interaction between bacterial overgrowth and GUS expression in context with co-culture period of explants in bacterial suspension

\subsection{Type of explants}

Transformation ability of various explants, namely, DE, CN and CADE of BM-4, BM-5 and BM-6 variety of lentil was monitored through the expression of the GUS gene following incubation for a period of 45 minutes with Agrobacterium strain LBA4404 having an O.D. of 1.0 and co-cultivation for $72 \mathrm{hrs}$. GUS expression was detected by histochemical assay and such expression was characterized by the formation of indigo blue colour within the transformed cells of the infected explants. Control explants were always maintained in each set of experiment and were subjected to GUS histochemical assay in order to understand the difference between transformed and non-transformed tissue. Results of these experiments are presented in table 3.

Table 3 Responses of various explants of BM - 4 variety of lentil towards GUS histochemical assay following cocultivation

\begin{tabular}{llccc}
\hline Variety & Explants & $\begin{array}{c}\text { Number of } \\
\text { explants assayed } \\
\text { for GUS }\end{array}$ & $\begin{array}{c}\text { Number of GUS+ve } \\
\text { explants }\end{array}$ & $\begin{array}{c}\text { Percentage of } \\
\text { GUS+ve explants } \\
\text { (\%) }\end{array}$ \\
\hline BM-4 & CN & 95 & 53 & 55.79 \\
& CADE & 85 & 72 & 77.70 \\
\hline BM-5 & CN & 90 & 70 & 84.70 \\
\hline & CADE & 146 & 47 & 32.19 \\
\hline BM-6 & CN & 126 & 105 & 75.38 \\
& CADE & 120 & 91 & 83.33 \\
\hline${ }^{*}$ CN= Cotyledonary node, CADE $=$ Cotyledon attached decapitated embryo, DE= decapitated embryo
\end{tabular}

A good number of co-cultured explants showed positive to GUS staining. GUS positive regions were visualized mostly at the peripheral area of the cut surfaces as well as within the internal tissues of various explants (fig. 3A- D).

Prominent blue coloured (GUS+ve) zones within co-cultured explants were visualized under stereomicroscope. In some cases the whole explant appeared to be blue in colour (fig. 3E) but in other cases this blue colour was localized in some 
specific areas of the explant (fig. 3F). It was evident from table 3 that, DE explants showed the best response towards transformation with LBA4404 strain and the percentage of GUS positive DE explants was 86.9 in case of BM-6 variety of lentil. Next to DE explants CADE explants showed better responses towards transformation and in this case the percentage of GUS positive explants was found to be 78.18. In case of CN explants highest percentage of GUS positive explant were 58 in case of BM-6 which appeared to be the lowest among the three explants studied. This result is almost similar to the earlier results reported by Sarker et al. [25], Hassan et al.[26] and Das et al. [27] in lentil.

In some cases, much greater areas of explants exhibited GUS expression while in other cases only a small portion of the wounded tissue were competent for transformation. Similar results regarding the expression of the GUS gene in lentil tissue have been reported by Warkentin and McHughen [24] in lentil.

\subsection{Effect of growth regulators in the co-cultivation media}

The composition of co-culture media particularly the hormonal supplements is also influence transformation efficiency of Agrobacterium. In the present study it was observed that presence of growth regulator in co-culture media enhance the induction of adventitious shoots and found to improve the health of regenerated shoots. Schroeder et al. [28] reported that in case of Pisum sativa presence of growth regulators in the co-cultivation media enhanced recovery of putative transgenic plants. In chickpea, Kar et al. [29] reported that absence of growth regulators in co-cultivation media greatly reduced transformation efficiency and recovery of transgenic plants.
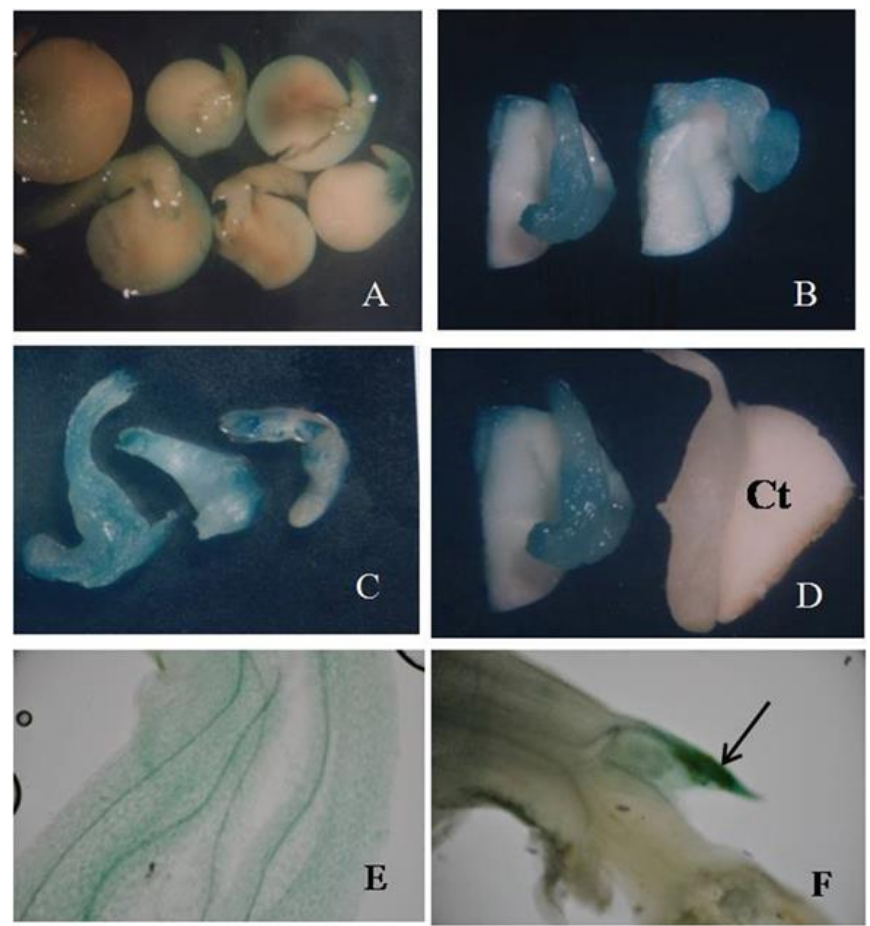

Figure 3 GUS activity in explants. A-Histochemical localization of GUS activity in explants of CN $\times 20$. B- Same as fig. A but in case of CADE explants $\times 20$. C- Same as fig. A but in case of DE explants $\times 20$. D- Same as fig. B, but showing the absence of GUS activity in control (Ct) explants $\times 20$. E- Magnified view of internal tissue showing positive GUS expression conspicuous blue color in whole explant. F- Same as fig. E, showing localized blue color within the internal tissue (arrow) of CADE explant

\section{Conclusion}

An efficient protocol for Agrobacterium mediated genetic transformation in lentil was developed which showed transfer of marker genes (GUS and nptII). DE explants showed highest transformation frequency having an optical density (O.D.) of 1.0 with 45 minutes of incubation and 3 days of co-cultivation. Next to DE, CADE showed positive response towards Agrobacterium mediated genetic transformation but this explants showed highest frequency of regeneration and survival rate. Further molecular analysis like PCR, southern and northern hybridization, RT PCR etc. to be needed to confirm transformation of putative transformants. Thus in further investigation agronomically and economically important traits could be transfer to the locally grown lentil varieties using this protocol. 


\section{Compliance with ethical standards}

\section{Acknowledgments}

The authors are grateful to Professor Dr. M. M. Haque, Department of Botany, University of Dhaka for his suggestions during the preparation of this manuscript and critically going through it.

\section{Disclosure of conflict of interest}

The authors declare that they have no conflict of interests. Subroto K. Das conducted the experiments, including statistical analyses and mainly wrote the manuscript. R. H. Sarker and M. I. Hoque supervised the experiments and gave suggestion in preparing manuscript.

\section{References}

[1] Monti L, Biddle Aj, Moreno MT and Plancquarte P. (1994). Biotic and abiotic stresses of pulse crops in Europe. In: F. J. Muehlbauer and K. J. Kaiser (Eds.), Expanding the Production and Use of Cool season Food Legumes, Kliuwer Academic Publishers, Dordrecht, the Netherlands, 204 -18.

[2] Saxena MC. (1993). The challenge of developing biotic and abiotic stress resistance in cool-season food legumes. In: K. B. Singh and M. C. Saxena (Eds.), Breeding for stress Tolerance in cool season FOOD LEGUMES, Wiley, Chichester, United Kingdom, 3-14.

[3] Slindard AE, Bascur G and Hernandez-Bravo G. (1994). Biotic and abiotic stesses of cool-season food legumes in the Western Hemisphere. In: F. J. Muehlbauer and K. J. Kaiser (Eds.), Expanding the Production and Use of Cool season Food Legumes, Kliuwer Academic Publishers, Dordrecht, The Netherlands, 195-203.

[4] Arokiaraj P, Rueker F, Obermayr E, Shamsul Bahri AR, Hafsah J, Carter DC and Yeang HY. (2002). Expression of human serum albumin in transgenic Hevea brassilensis. J. Rubber Research, 5, 157 -66.

[5] Gulati A, Schryer P and McHugen A. (2002). Production of fertile transgenic lentil (Lens culinaris Medik) plants using particle bombardment. In vitro Cell Dev. Biol.-Plant, 38, 316 -24.

[6] Masood ZH, McMullen MD and Finer JJ. (1996). Transformation of 12 different plasmids into soyabean via particle bombardment. Plant Cell Reports, 15, 500 -05.

[7] Öktem HA, Mahmoudian M, Eyidodan F and Yucel M. (1999). GUS gene delivary and expression in lentil cotyledonary nodes using particle bombardment. Lens Newsletter. 26(1 and 2), 3-6.

[8] Gardner RC. (1993). Gene transformation into tropical and subtropical crops. Scientia Horticulture, 55, 65-82.

[9] Ding LC, Hu CY, Yeh KW and Wang PJ. (1998). Development of insect resistant transgenic cauliflower plants expressing the trypsin inhibitor gene isolated from local sweet potato. Plant Cell Reports, 17(11), 854 -60.

[10] Zhang FL, Takahata Y, Watanabe M and Xu JB. (2000). Agrobacterium-mediated transformation of cytoledonary expalnts of Chinese cabbage (Brassica campestris L. spp. pekinensis). Plant Cell Reports, 19, 569 -75.

[11] Krishnamurthy KV, Suhasini K, Sagare AP, Meixner M, De Kathen A, Pickardt T and Schieder 0. (2000). Agrobacterium-mediated genetic transformation of chickpea (Cicer arietinum L.) embryo axes. Plant Cell Reports, 19, $235-40$.

[12] Herrea- Esterella L, Depicker A, Montagu M and Schell J. (1983). Expression of chimeric gene transferred into plant cells using a Ti-plasmid derived vector. Nature, 303, 209.

[13] Hooykaas PJJ. (1988). Agrobacterium molecular genetics. Plant Molecular Biology Manual, 4, 1-13.

[14] Jefferson RA, Kavanagh TA and Bevan MW. (1987). GUS fusion: Beta-glucoronidase as a sensitive and versatile gene fusion marker in higher plants. EMBO J., 6, 3901 -07.

[15] Gould JH and Smith RH. (1997). A non-destructive assay of GUS in the media of plant tissue cultures. Plant Molecular Biology Reports, 7, 209 -16.

[16] Jaiwal PK, Sautter C and Potrykus I. (1998). Agrobacterium rhizogenes mediated gene transfer in mung bean (Vigna radiata (L.) Wilczek). Current Science, 75, 41 -45. 
[17] Jaiwal PK, Kumari R, Ignacimuthu S, Potrykus I and Curistos S. (2001). Agrobacterium tumefaciens genetic transformation of mungbean (Vigna radiata L. wilczek.): A recalcitrant grain legume. Plant Science, 161,239 -47.

[18] Zhang H, Huang QM and Su J. (2010). Development of alfalfa (Medicago sativa L.) regeneration system and Agrobacterium- mediated genetic transformation. Agricultural Science, 9(2), 170 -78.

[19] Abullah R, Zainal A, Heng WY, Li LC, Beng YC, Phing LM, Sirajuddin SA, Ping WYS, Joseph JL, Jusoh SA, Murad MR and Huey YL. (2005). Immature embryo: a useful tool for oil palm (Elaeis guineensis Jacq.) genetic transformation studies. J. Biotechnology, 8, 24 -34.

[20] Kathen Ade and H Jacobsen. (1990). Agrobacterium tumefaciens mediated transformation of Pisum sativum L. using binary and co-integrate vectors. Plant Cell Reports, 9, 176 -79.

[21] Horsch RB, Fry J, Hoffmann M, Wallroth M, Eichholtz D, Rogers S and Fraley RT. (1985).A simple and general method for transferring genes into plants. Science, 227, 1229 -31.

[22] Arundhati, A. (1999). Agrobacterium mediated transformation of pigeon pea by using leaf disks. International Chickpea and Pigeon pea Newsletter, 6, 62-64.

[23] Tewari-Singh N, Sen J, Kiesecker H, Reddy VS, Jacobson HJ and Mukherjee SG. (2004). Use an herbicide or lysine plus threonine for non-antibiotic selection of transgenic chickpea. Plant Cell Reports, 22, 576 -83.

[24] Warkentin TD and McHughen A. (1992). Agrobacterium tumefaciens-mediated beta-glucoronidase (GUS) gene expression in lentil (Lens culinaris Medik.) tissues. Plant Cell Reports, 11, 274 -78.

[25] Sarker RH, Mustafa BM, Biswas A, Mahbub S and Hoque MI. (2003). Agrobacterium -mediated transformation of lentil (Lens culinaris Medik.). Plant Tissue Culture, 13(1), 1-12.

[26] Hassan F, Hoque MI, Kiesecker H and Jacobsen H. (2007). Transient Gus Expression in decapitated lentil embryos. Plant Tissue Cult. \& Biotechnology, 17(1), 97-102.

[27] Das SK, Shethi KJ, Hoque MI and Sarker RH. (2012). Agrobacterium mediated genetic transformation in lentil (Lens culinaris Medik.) followed by in vitro flowering and seed formation. Plant Tissue Cult \& Biotechnology, 22(1), $13-26$.

[28] Schroeder HE, Schotz AH, Wardely T, Richardson T, Richardson D and Spencer TJV. (1993). Transformation and regeneration of two cultivars of pea (Pisum sativum L.) Plant Physiology, 101, 751 -57.

[29] Kar S, Johanson TM, Nayak P and Sen SK. (1996). Efficient transgenic plant regeneration through Agrobacteriummediated transformation of chickpea. Plant Cell Reports, 16, 32 -37.

\section{How to cite this article}

Das SK, Hoque MI and Sarker RH. (2018). Study of different factors affecting Agrobacterium- mediated genetic transformation in lentil (Lens culinaris Medik.). GSC Biological and Pharmaceutical Sciences, 5(1), 34-42. 